\title{
CONSIDERACIONES SOBRE LAS RAÍCES DE LA CRISIS ACTUAL DE LA CULTURA OCCIDENTAL \\ Roberto Zocco*
}

En primer lugar, me gustaría agradecer al profesor Parens por su presentación muy interesante. En mi breve respuesta, simplemente quiero centrarme en dos conceptos de la tradición occidental que, en mi opinión, explican por qué esta cultura tiene sus raíces en el cristianismo, como también sostiene Brague. E1 primer concepto es el de Dios y el segundo es el de la razón. Mi respuesta consiste en tres partes. En primer lugar, trataré la relación entre razón y Dios. En segundo lugar, hablaré del encuentro del cristianismo con otras culturas. En tercer lugar, expondré la necesidad de recuperar un concepto adecuado de la razón y la libertad.

\section{Identificación de Dios con la razón}

Las raíces de la cultura occidental se basan en el concepto de Dios. No se trata de un simple monoteísmo, sino del encuentro entre el monoteísmo bíblico y el monoteísmo filosófico de los griegos. Esta distinción me parece importante porque, como veremos, el monoteísmo islámico es muy diferente.

En la tradición cristiana, Dios es el logos, es decir, Dios actúa de acuerdo con la razón.

Este concepto ya está en el primer versículo de la Biblia, en el libro del Génesis (en la traducción del hebreo al griego conocida como la

* Departamento Académico de Estudios Generales, ITAM. 
Septuaginta, está la palabra “logos”). Juan el Evangelista, en el prólogo de su Evangelio, para identificar a Dios usa la palabra griega razón "logos". La misma palabra se encuentra en la tradición filosófica griega y se atribuye principalmente a Dios. Como el hombre es creado a imagen y semejanza de Dios, es el único ser dotado de razón. Así que hay cierta analogía entre el espíritu creativo y la razón humana, según la cual el hombre puede entender el misterio de Dios sin comprenderlo por completo. ${ }^{1}$

De acuerdo con este punto de vista, entonces, ir contra la razón es ir en contra de la naturaleza de Dios. Por otra parte, el hombre, como criatura racional, es llamado por Dios a utilizar su capacidad racional en el mundo. Dios quiere que el hombre lo conozca para que pueda entrar en su misterio, aunque este conocimiento nunca será completo. En resumen, Dios se revela a sí mismo y habla a la razón del hombre, así como a su corazón.

En el islam nos encontramos con un concepto diferente de Dios. Dios, como en el cristianismo, es trascendente. Pero, a diferencia del Dios de la tradición judeocristiana, permanece encerrado en su trascendencia. Aunque Dios, según lo que dice el Corán, hable a Mahoma, sigue siendo trascendente y nunca se encarna. Por esta razón, el islam tiene también un concepto muy distinto de la historia. Es un Dios totalmente diferente del ser humano que no puede ser ni entendido ni conocido, porque es ajeno a la razón humana. En este caso, la relación del hombre con Dios se establece únicamente mediante la sumisión a la voluntad de Dios. No sorprende, entonces, que la misma palabra "islam" signifique "sumisión".

Para una ulterior comparación, podemos decir que ambos conceptos de Dios exigen la obediencia del hombre a una voluntad que lo precede y lo supera (usamos la palabra "tradición" o incluso la palabra "fe"). La diferencia entre las dos imágenes de Dios es la siguiente. En la tradición cristiana, Dios llama al hombre a obedecer primero y luego a ser conocido. En la tradición islámica, Dios llama al hombre solo para

${ }^{1} C f$. IV Concilio de Letrán 1215. 
obedecer, sin que este pueda comprenderlo a Él ni entender su voluntad. Nuestros conceptos de bondad, justicia, verdad, orden, maldad, etc., son nada más nuestros y no de Dios.

Si reflexionamos sobre la diferencia entre el concepto de Dios de la tradición judeocristiana, por una parte, y la tradición islámica, por la otra, se concluye que en esta última la separación entre la razón y la revelación, entre la razón y la fe, y entre la naturaleza y la tradición (para usar conceptos presentados por mi colega) está presente desde el principio, mientras que en la primera tradición, la razón, la tradición y la revelación están unidas desde el principio. Esta primera conclusión no quiere ser categórica, sino solo indicativa de una tendencia. A lo largo de la historia en ambas tradiciones ha habido excepciones.

Estas observaciones fueron presentadas exhaustivamente en el discurso que el Papa Benedicto XVI pronunció en la Universidad de Ratisbona en $2006^{2}$ y cuya lectura recomiendo vivamente.

\section{La actitud peculiar del cristianismo frente a otras culturas}

Una de las cosas que más me sorprende cuando estudio la expansión del cristianismo primitivo y el nacimiento de Europa es que es el resultado del encuentro entre tres culturas. Me parece que este hecho no es muy común en la historia. Creo, por tanto, que vale la pena detenerse un momento para reflexionar sobre cómo fue posible este encuentro entre culturas.

Ya he puesto de relieve una primera toma de contacto entre la cultura filosófica griega y la judeocristiana (el concepto de Dios como logos, razón). Ahora me gustaría explicar la actitud positiva de los primeros cristianos ante la cultura griega y la cultura romana, que puede describirse brevemente con las palabras de San Pablo: "Examínenlo todo; quédense con lo bueno" (1 Tes 5,21).

${ }^{2}$ Cf. Papst Benedikt XVI, Apostolische Reise nach München, Altötting und Regensburg, 9.-14. September 2006, Treffen mit den Vertretern aus dem Bereich der Wissenschaften, Ansprache, en: <http://w2.vatican.va/content/benedict-xvi/de/speeches/2006/september/documents/hf_benxvi_spe_20060912_university-regensburg.html > (consultado el 9 de agosto de 2015). 
Esta actitud positiva frente a las diferentes culturas y tradiciones tiene sus raíces en la fe de la Encarnación de Dios y en la creencia de que el mundo ha sido creado en y por Cristo. Los cristianos piensan que si Dios no ha desdeñado la naturaleza humana, sino que la asumió en su naturaleza divina, es porque Él valora todo lo que es humano. Por otra parte, si ha creado cada cosa en y por Cristo, que es el logos, se puede encontrar una huella de Cristo en todo lo que existe. Por lo tanto, los cristianos creen que al mirar a Cristo, pueden valorar lo humano que hay en cada individuo, en cada cultura, en cada tradición.

Esta creencia cristiana ha hecho posible la asimilación de diversos aspectos de la cultura griega y romana, como, por ejemplo, algunas ideas sobre la educación.

De esta manera, el encuentro con otras culturas y tradiciones no se ha dado a partir de una posición rígida, sino de una vida vivida, la cual se comunicaba, en medio de muchas tensiones y problemas, de persona a persona.

También debemos decir algo más del otro lado. La cultura humana es la forma de ordenar la vida humana y el mundo a la luz de lo que un pueblo dado considera el principio (ser o seres) que lo explica todo. Sin embargo, la cultura humana es siempre incompleta, es decir, que siempre está abierta a buscar una mejor manera de explicar y ordenar la vida y el mundo. Los pueblos que el cristianismo encontró (griegos, romanos, alemanes, indios americanos, asiáticos, etc.) buscaban igualmente una comprensión más verdadera de su manera de vivir. Esta es también la razón de la expansión a la que hacía referencia al principio de esta ponencia, la cual no era ni una imposición ni la asimilación de las otras culturas. Era, sí, una purificación de lo que no tenían de verdadero (por ejemplo, los sacrificios humanos), pero también una confirmación y una profundización de lo que era verdadero (la razón, la libertad).

Me gustaría insistir en la conclusión de esta segunda parte de mi respuesta, en la que encontramos una unión entre la razón y la revelación, entre la fe y la razón, entre la naturaleza y la tradición, que me parece que son las raíces de la cultura occidental. 


\section{La separación entre fe y razón es debida a un cambio del concepto de razón}

Es innegable, pues, que la cultura occidental ha entrado en crisis. Tanto la libertad como la razón han perdido su verdadero significado. Vamos a considerar la libertad primero y luego volveremos al concepto de la razón.

\section{Libertad}

Uno de los signos más preocupantes para mí de esta crisis radica en el hecho de que algunos jóvenes en Europa, a pesar de que nacieron y se criaron en esta cultura y en esta tradición, decidieron dejarlo todo para abrazar las armas y la guerra santa del islam radical por odio a la sociedad en la que crecieron.

Lo importante no es tanto el número de estos jóvenes, sino el significado del fenómeno. Si estos jóvenes han llegado a odiar a la sociedad en la que crecieron, significa que esta sociedad se está muriendo porque ya no es atractiva, porque no ofrece algo que los jóvenes buscan y que piensan haber encontrado en su odio hacia esta misma sociedad.

Antes de considerar la forma con la que quieren afirmar el ideal que reconocen como verdadero, es decir, con la violencia, me impresiona que renuncien al aspecto que consideramos más característico y aclamado de la cultura occidental, a saber, la libertad, para abrazar la subyugación. En este sentido me gustó la última novela de Michel Houellebecq, Sumisión, ${ }^{3}$ en la que el protagonista ya no tiene fuerzas para afirmar su libertad y decide someterse al islam.

La fuga de estos jóvenes del mundo occidental y su entrega a una vida de sumisión revelan una vez más que el concepto de libertad — que en el cristianismo no es la libertad de coacción, sino la libertad para el fin o destino para el que uno ha sido hecho- está desapareciendo de la sociedad europea. Este concepto de libertad debe ayudar a identificar un significado en la vida y a perseguirlo. En cambio, queda solo un

\footnotetext{
${ }^{3}$ Houellebecq, Sottomissione, 2015, Milán, Bompiani, trad. al italiano de Vincenzo Vega.
} 
concepto de libertad de hacer, de experimentar. Creo que la idea sartreana de libertad como condena está muy extendida en Occidente. La libertad es una condena solo cuando uno no sabe a dónde conduce, porque todas las opciones son iguales.

Creo que la cultura occidental está privando a los jóvenes de una de las cosas más necesarias en la vida: la búsqueda del sentido de su existencia, de su destino. Para ser verdaderamente libres, es necesario reconocer un fin en la vida y elegir así lo que es correcto. Para ser verdaderamente libres se debe, por lo tanto, hacer un esfuerzo continuo; un esfuerzo que implica crecer y madurar, cometer errores y levantarse. La elección de la sumisión es, después de todo, una elección fácil, porque se delega a los demás las elecciones que deberían ser nuestras. Veamos ahora el concepto de razón.

\section{Razón}

Reconocer el fin o el propósito de la vida es una tarea de la razón. La razón es el otro concepto que está en crisis en la cultura occidental. Hasta la Edad Media, la razón estaba en armonía con la fe y la tradición, pero ahora nos encontramos frente a dos conceptos que siguen caminos diferentes y, en ocasiones, opuestos.

Para describir el cambio que ha sufrido el concepto de razón en el Occidente, me gusta usar el ejemplo de uno de mis maestros: hasta la Edad Media, la razón era como una ventana abierta a la realidad, ${ }^{4}$ mientras que ahora se ha vuelto una habitación sin ventanas (en otros términos la razón se ha vuelto la medida de la realidad y considera poder explicar todo plenamente sin ninguna referencia a Dios). ${ }^{5}$ En el primer caso, la razón siempre ha reconocido algo en la realidad que no puede ser medido, algo que excede su capacidad de entendimiento. Conside-

${ }^{4}$ Luigi Giussani, Il senso di Dio e l'uomo moderno: La «questione umana» e la novità del Cristianesimo, 2010, Milán, BUR, p. 98.

${ }^{5}$ Cf. Papst Benedikt XVI, Apostolische Reise nach Deutschland, 22.-25. September 2011, Besuch des Deutschen Bundestags, Ansprache, en: <https://w2.vatican.va/content/benedict-xvi/ de/speeches/2011/september/documents/hf_ben-xvi_spe_20110922_reichstag-berlin.html> (consultado el 9 de agosto de 2015). 
rando la relación entre la razón y la tradición, en la Edad Media la razón era llamada primero a obedecer y, luego, a entender. En el segundo caso, la razón moderna se identifica con su capacidad de medir y de entender. Por lo tanto, cualquier cosa que no pueda ser medida, o no existe o se vuelve irrelevante.

En mi opinión, el Occidente cristiano debería recuperar el significado original de estas dos palabras, libertad y razón, si quiere salir de su profunda crisis; al mismo tiempo, esto facilitaría un diálogo fructífero con el islam.

Como mi colega reconoció, también en el islam se han producido a lo largo de la historia diferentes corrientes de las que ahora dominan, las cuales han sido capaces de unir la razón y la revelación, la razón y la fe, la naturaleza y la tradición.

Por otra parte, pienso también que el escepticismo de Brague sobre la posibilidad del islam de entablar el diálogo con la cultura occidental deriva más de la actual falta de una filosofía islámica, y no de una falla intrínseca del propio islam. ${ }^{6}$

Aunque comparta el escepticismo de Brague, mantengo la esperanza, porque veo que en el mundo islámico hay personas que reconocen la necesidad de una reforma, así como lo expresó el $1^{\circ}$ de enero de este año el presidente egipcio, el general Abdelfatah al-Sisi, en la Universidad al Azhar de El Cairo.

${ }^{6}$ Remi Brague y Giulio Brotti, Dove va la storia? Dilemmi e speranze, 2015, Brescia, La Scuola, p. 65. 
CITAM Derechos Reservados.

La reproducción total o parcial de este artículo se podrá hacer si el ITAM otorga la autorización previamente por escrito. 